\title{
A Novel Compound Heterozygous Tyrosine Hydroxylase Mutation (p.R441P) with Complex Phenotype
}

\author{
Kristoffer Haugarvoll ${ }^{\mathrm{a}, *}$ and Laurence A. Bindoff ${ }^{\mathrm{a}, \mathrm{b}}$ \\ ${ }^{a}$ Department of Neurology, Haukeland University Hospital, Bergen, Norway \\ ${ }^{\mathrm{b}}$ Department of Clinical Medicine, University of Bergen, Bergen, Norway
}

\begin{abstract}
Tyrosine hydroxylase (TH) is a tetrahydrobiopterin (BH4) dependent enzyme that catalyses the conversion of Ltyrosine to L-dopa, the rate-limiting step in the biosynthesis of dopamine. Autosomal recessive mutations in the $T H$ gene cause impaired TH activity and are associated with phenotypes ranging from autosomal recessive dopa-responsive dystonia (DRD) to progressive infantile encephalopathy.

Herein, we present a patient with TH-deficiency due to two compound heterozygous missense mutations in the $T H$ gene, one of which is novel (p.R441P). A clinical update on TH-deficiency and clues on how to achieve a timely diagnosis of this highly treatable disorder is provided.
\end{abstract}

Keywords: Dopa-responsive dystonia, spastic paraplegia, levodopa, parkinsonism, Segawa syndrome

Tyrosine hydroxylase (TH, EC 1.14.16.2) is a tetrahydrobiopterin (BH4) dependent enzyme that catalyses the conversion of L-tyrosine to L-dihydroxyphenylalanine (L-dopa), the rate-limiting step in the biosynthesis of dopamine (figure). TH-deficiency [OMIM number 191290] is associated with heterogeneous phenotypes, including autosomal recessive L-dopa-responsive dystonia (DRD/Segawa syndrome) [1, 2], dopa-responsive infantile parkinsonism [3], dopa-responsive pseudo-spastic paraplegia $[4,5]$, and progressive infantile encephalopathy [6, 7]. All DRDassociated mutations cause reduced $\mathrm{TH}$-activity with preservation of nigrostriatal terminals. TH-deficiency is caused by $T H$ gene mutations, while GTP cyclohydrolase $1(\mathrm{GCH})$ and sepiapterin reductase (SPR) gene mutations lead to impaired synthesis of the THcofactor tetrahydrobiopterin (BH4) $[5,8,9]$.

\footnotetext{
${ }^{*}$ Correspondence to: Kristoffer Haugarvoll, MD PhD, Department of Neurology, Haukeland University Hospital, Jonas Liesvei 65, NO-5021 Bergen, Norway. Tel.: +47 559750 44; Fax: +47 55 97 5164; E-mail: haugarvoll@gmail.com.
}

Pure DRD is defined as isolated dystonia with a sustained response to low doses of L-dopa and no other neurological manifestations except mild parkinsonism [5]. DRD-plus syndromes are associated with other neurological features including mental retardation, psychiatric manifestations, oculogyric crises, ptosis, axial hypotonia and dysautonomia $[5,10]$.

We report a patient with a novel compound heterozygous mutation in the $\mathrm{TH}$ gene.

The patient is a man of 27 years. His family history is unremarkable except for a paternal grandfather with multiple sclerosis. Pregnancy, delivery and the neonatal period were normal, but delayed motor development was apparent in the first year of life. He crawled at age nine months, could not sit unassisted until 12 months of age and his sitting balance was poor, consistent with axial hypotonia. He was admitted to hospital aged 14 months due to episodes of tremor of his head, trunk and arms that had started two months previously. These tremor episodes were symmetrical and usually occurred when the patient was tired or excited and disappeared after six months. He walked at age $2 \frac{1}{2} 2$ years, 
A

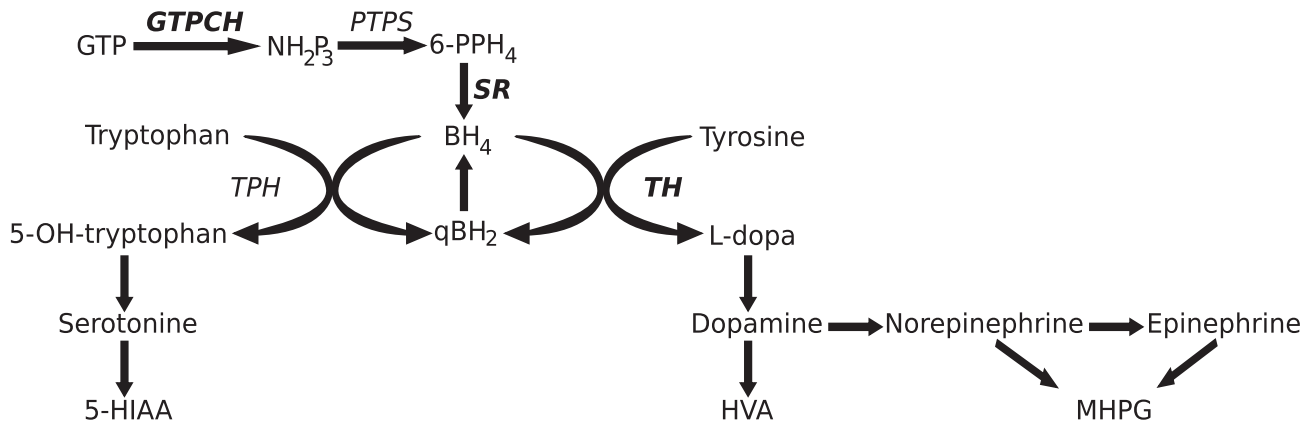

B

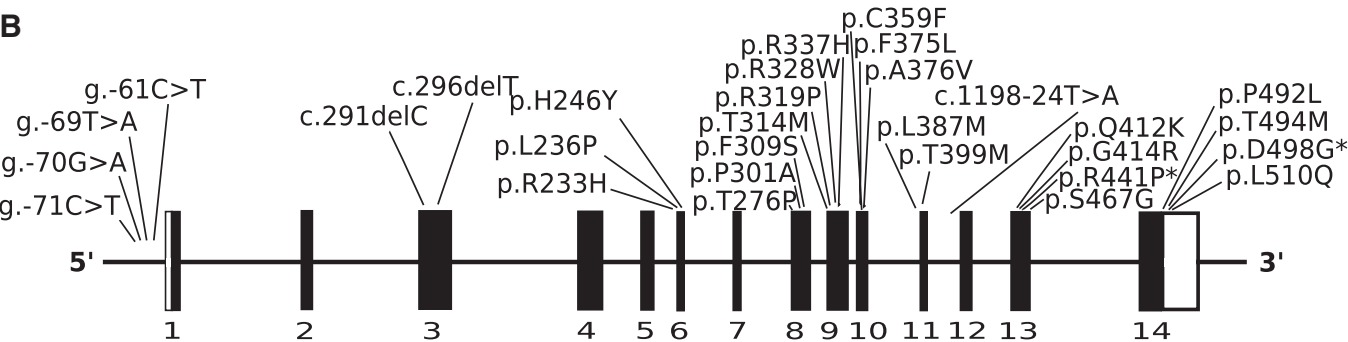

Fig. 1. (A) Biochemical pathway of serotonin and catecholamine metabolism. Guanosine triphosphate (GTP), GTP cyclohydrolase 1 (GTPCH), dihydroneopterin triphosphate $\left(\mathrm{NH}_{2} \mathrm{P}_{3}\right)$, 6-pyruvoyl tetrahydropterin synthase (PTPS), 6-pyruvoyl-tetrahydropterin (6PPH $)_{4}$, sepiapterin reductase (SR), tryptophan hydroxylase (TPH), tetrahydrobiopterin (BH4), quinoid dihydrobiopterin $\left(\mathrm{qBH}_{2}\right)$, tyrosine hydroxylase $(\mathrm{TH})$. 5hydroxyindolacetic acid (5-HIAA), homovanillic acid (HVA), 3-methoxy-4-hydroxyphenylglycol (MHPG). (B) TH gene mutations. Schematic representation of the $T H$ gene. Mutations identified within the $T H$ gene are indicated (refs. 4 and 6 ). *Mutations identified in this study. Numbering of coding sequence mutations is according to GenBank reference sequence NM 199292.1.

but his balance remained poor with both spasticity and inward rotation of the legs present, consistent with pseudo-spastic paraplegia. Speech was dysarthric, but language development normal. Motor skills gradually improved until about five years of age.

His condition deteriorated following pneumonia aged 6 years and subsequently he experienced periodic worsening lasting several months after infections. During these episodes he became tired, floppy and his dysarthria worsened, but the motor features suggesting dystonia appeared unchanged. He became wheelchair-bound around age 9 years when examination showed a pseudo-spastic tetraplegia, including hyperreflexia and extensor plantar response bilaterally. The hyperreflexia and extensor plantar response were interpreted as pyramidal signs. Abdominal reflexes were present. Dysarthria increased in severity and he developed episodes of drop-head. The patient experienced marked diurnal fluctuations with worsening during the day and improvement after sleep. Fatigue gradually became chronic. There were no signs of mental retardation, but his education suffered due to blurred vision that occurred with sustained reading. Routine laboratory tests, cerebral MRI, lumbar puncture and muscle biopsy were all normal.

At age 25 years he developed rigidity and resting tremor. Cogwheel rigidity was not present. At this point levodopa treatment was tried, leading to dramatic symptomatic improvement. The plantar responses became flexor. On $300 \mathrm{mg}$ levodopa daily he is able to walk 15-20 meters using crutches and ascend two flights of stairs. His dystonia has improved and his dysarthria and blurred vision have vanished enabling him to resume his education. The diagnosis was confirmed by mutation screening by sequencing and multiplex ligation dependent probe amplification (MLPA) at Kennedy Centret, Medical Genetics Laboratory,

Glostrup, Denmark [11]. No mutations or deletions were identified in the $\mathrm{GCH} l$ gene. The patient was compound heterozygous for two $\mathrm{TH}$-missense mutations: c. $1322 \mathrm{G}>\mathrm{C}$ (p.R441P) and c.1493A > G (p.D498G) [4]. The p.R441P mutation is novel and R441 is highly conserved across species (figure). This genetic finding in combination with the distinct, levodopa-responsive phenotype seen in this patient makes it highly likely that the c.1322 G > C (p.R441P) 
mutation is pathogenic. The delayed diagnosis in this patient allows a description of the natural course of TH-deficiency.

DRD/Segawa syndrome is characterized by infantile to young-onset dystonia, diurnal fluctuations and parkinsonism. GCHl gene mutations are the most common cause of autosomal dominant DRD [5, 12]. Another patient in our clinic had classic autosomal recessive DRD due to compound heterozygous mutations in the $T H$ gene (c.689 G > A/p.R233H and c.1240 G > A/p.G414 R) [13, 14]: This second patient had normal motor development and started walking at age one year. He developed inward rotation of legs during walk at age 5-6 years. The symptoms increased in severity during the day and when he was tired. Several years after onset of the disease he developed rest tremor and pyramidal signs, including extensor plantar response. He experienced dramatic improvement with low dose L-dopa treatment.

TH-deficiency more often causes complex syndromes however, and as our case highlights, should be considered in all patients displaying delayed psychomotor development of unknown cause $[7,15]$. Very recently, TH-deficiency patients have been divided into two main clinical subgroups; an infantile onset, progressive, hypokinetic-rigid syndrome with dystonia (type A) and a complex encephalopathy with neonatal onset (type B) [7]. Type A TH-deficiency patients have onset of symptoms within the first five years of life. Type B TH-deficiency patients have onset within the first months of life and fetal distress may be the first symptom [6]. In contrast to the excellent L-dopa response observed in type A TH-deficiency patients, type B patients often exhibit only mild and delayed improvement on L-dopa. Mental retardation is present in a minority of type A TH-deficiency patients, in contrast it is observed in most type B patients. Our patient would be classified as type A TH-deficiency.

Metabolic diagnosis in cerebrospinal fluid (CSF) maybe helpful in diagnosing TH-deficiency [7, 16]. Analysis of a standardized CSF fraction reveals decreased levels of homovanillic acid (HVA) and 3methoxy-4-hydroxyphenylglycol (MHPG) and normal 5-hydroxyindoleacetic acid (5-HIAA) and a decreased HVA/5-HIAA ratio (figure). Standardized CSF analysis and mutation analysis of the $T H$ gene may be helpful to avoid the diagnostic delay observed in the patient reported here. Importantly, a levodopa trial should be carried out in all children with an unexplained movement disorder, especially when tremor or dystonia is present.

\section{ACKNOWLEDGMENTS}

Written informed consent was obtained from the patient for publication of this case report. A copy of the written consent is available for review by the Editorin-Chief of this journal. The authors declare that they have no competing interests.

\section{REFERENCES}

[1] $\mathrm{OMIM}^{\circledR}$ - Online Mendelian Inheritance in Man $^{\circledR}$, http:// www.ncbi.nlm.nih.gov/omim.Accessed

[2] Knappskog PM, Flatmark T, Mallet J, Ludecke B, \& Bartholome K (1995) Recessively inherited L-DOPAresponsive dystonia caused by a point mutation $(\mathrm{Q} 381 \mathrm{~K})$ in the tyrosine hydroxylase gene. Hum Mol Genet, 4, 1209-1212.

[3] Ludecke B, Knappskog PM, Clayton PT, Surtees RA, Clelland JD, Heales SJ, Brand MP, Bartholome K, \& Flatmark T (1996) Recessively inherited L-DOPA-responsive parkinsonism in infancy caused by a point mutation (L205P) in the tyrosine hydroxylase gene. Hum Mol Genet, 5, 1023-1028.

[4] Furukawa Y, Graf WD, Wong H, Shimadzu M, \& Kish SJ (2001) Dopa-responsive dystonia simulating spastic paraplegia due to tyrosine hydroxylase (TH) gene mutations. Neurology, 56, 260-263.

[5] Clot F, Grabli D, Cazeneuve C, Roze E, Castelnau P, Chabrol B, Landrieu P, Nguyen K, Ponsot G, Abada M, Doummar D, Damier P, Gil R, Thobois S, Ward AJ, Hutchinson M, Toutain A, Picard F, Camuzat A, Fedirko E, San C, Bouteiller D, LeGuern E, Durr A, Vidailhet M, \& Brice A (2009) Exhaustive analysis of $\mathrm{BH} 4$ and dopamine biosynthesis genes in patients with Dopa-responsive dystonia. Brain, 132, 1753-1763.

[6] Hoffmann GF, Assmann B, Brautigam C, Dionisi-Vici C, Haussler M, de Klerk JB, Naumann M, SteenbergenSpanjers GC, Strassburg HM, \& Wevers RA (2003) Tyrosine hydroxylase deficiency causes progressive encephalopathy and dopa-nonresponsive dystonia. Ann Neurol, 54(Suppl. 6), S56-65.

[7] Willemsen MA, Verbeek MM, Kamsteeg EJ, de Rijk-van Andel JF, Aeby A, Blau N, Burlina A, Donati MA, Geurtz B, Grattan-Smith PJ, Haeussler M, Hoffmann GF, Jung H, de Klerk JB, van der Knaap MS, Kok F, Leuzzi V, de Lonlay P, Megarbane A, Monaghan H, Renier WO, Rondot P, Ryan MM, Seeger J, Smeitink JA, Steenbergen-Spanjers GC, Wassmer E, Weschke B, Wijburg FA, Wilcken B, Zafeiriou DI, \& Wevers RA (2010) Tyrosine hydroxylase deficiency: a treatable disorder of brain catecholamine biosynthesis. Brain, 133, 1810-1822.

[8] Ichinose H, Ohye T, Takahashi E, Seki N, Hori T, Segawa M, Nomura Y, Endo K, Tanaka H, Tsuji S et al. (1994) Hereditary progressive dystonia with marked diurnal fluctuation caused by mutations in the GTP cyclohydrolase I gene. Nat Genet, 8, 236-242.

[9] Bonafe L, Thony B, Penzien JM, Czarnecki B, \& Blau $\mathrm{N}$ (2001) Mutations in the sepiapterin reductase gene cause a novel tetrahydrobiopterin-dependent monoamineneurotransmitter deficiency without hyperphenylalaninemia. Am J Hum Genet, 69, 269-277.

[10] Pons R, Serrano M, Ormazabal A, Toma C, Garcia-Cazorla A, Area E, Ribases M, Kanavakis E, Drakaki K, Giannakopoulos A, Orfanou I, Youroukos S, Cormand B, \& Artuch R (2010) 
Tyrosine hydroxylase deficiency in three greek patients with a common ancestral mutation. Mov Disord, 25(8), 1086-1090.

[11] Kennedy Centret, www.kennedy.dk., Accessed

[12] Wider C, Melquist S, Hauf M, Solida A, Cobb SA, Kachergus JM, Gass J, Coon KD, Baker M, Cannon A, Stephan DA, Schorderet DF, Ghika J, Burkhard PR, Kapatos G, Hutton M, Farrer MJ, Wszolek ZK, \& Vingerhoets FJ (2008) Study of a swiss dopa-responsive dystonia family with a deletion in GCH1: redefining DYT14 as DYT5. Neurology, 70, 13771383.

[13] van den Heuvel LP, Luiten B, Smeitink JA, de Rijk-van Andel JF, Hyland K, Steenbergen-Spanjers GC, Janssen RJ, \& Wevers RA (1998) A common point mutation in the tyrosine hydroxylase gene in autosomal recessive L-DOPA-responsive dystonia in the dutch population. Hum Genet, 102, 644-646.

[14] Giovanniello T, Leuzzi V, Carducci C, Sabato ML, Artiola C, Santagata S, Pozzessere S, \& Antonozzi I (2007) Tyrosine hydroxylase deficiency presenting with a biphasic clinical course. Neuropediatrics, 38, 213-215.

[15] Nygaard TG, Waran SP, Levine RA, Naini AB, \& Chutorian AM (1994) Dopa- responsive dystonia simulating cerebral palsy. Pediatr Neurol, 11, 236-240.

[16] Brautigam C, Wevers RA, Jansen RJ, Smeitink JA, de Rijk-van Andel JF, Gabreels FJ, \& Hoffmann GF (1998) Biochemical hallmarks of tyrosine hydroxylase deficiency. Clin Chem, 44, 1897-1904 